\title{
El complejo estructural de Guatin
}

RubÉn STehberg L.

Guatin corresponde a un plano inclinado de aproximadamente 80 ha (Lámina 1), muy disectado por lechos secos de estero, en el que se presentan 42 conjuntos de estructuras adaptadas al microrrelieve.

Su descripción, clasificación e interpretación constituyen el objeto de este informe, para lo cual nos apoyamos en un levantamiento topográfico del área con ubicación de las estructuras, descripción y representación gráfica de ellas, recolección superficial de cerámica y algunas excavaciones.

Se entiende por conjunto de estructuras al agrupamiento de varios recintos dentro de un área determinada y que se pueden relacionar con alguno de los otros conjuntos de acuerdo a uno o más de los siguientes criterios:

1. Ubicación topográfica. Se los ha subdividido de la siguiente manera:

a) En lecho seco de estero;

b) En superficies planas;

c) Al pie de las lomas de Guatin, y

d) Su cota relativa dentro del área.

La ubicación topográfica ha sido el principal criterio utilizado en la correlación de conjuntos. Así por ejemplo, todos los campos, que han sido construidos en lechos secos, fueron relacionados y representaron un patrón de poblamiento agrícola familiar característico.

2. Funcionalidad. Como segundo criterio hemos considerado las funciones de las distintas estructuras seleccionando principalmente las siguientes, por considerarlas más representativas:

a) Estructuras habitacionales;

b) Corrales;

c) Campos de cultivo, y

d) Bodegas.

Se han considerado como estructuras habitacionales a aquellas de tamaño reducido (entre 5 y $25 \mathrm{~m}^{2}$ ), que proporcionaron abundante material cerámico en la recolección superficial, con morteros asociados, y que si fueron excavadas presentaron gran número de fogones. Los corrales, en cambio, poseen tamaño mediano, entre 25 y $100 \mathrm{~m}^{2}$, forma preferentemente oval o circular, ausencia de divisiones interiores y escasez de restos culturales. Los campos de cultivo, generalmente poseen más de $100 \mathrm{~m}^{2}$, y a menudo, canales de regadío.

3. Arquitectura. Principalmente hemos considerado los siguientes elementos:

a) Material utilizado. La totalidad de los conjuntos estudiados utilizan en sus muros cantos rodados y bloques rocosos de gran abundancia en el área y que, salvo en el período reciente, no son canteados. Según su tamaño reciben la nominación de cantos rodados si poseen entre 6 y $25 \mathrm{~cm}$ y bloques si sobrepasan los $25 \mathrm{~cm}$;

b) Técnica de construcción. Para la mayoría de los conjuntos se ha utilizado la técnica de "piedra seca" o simple superposición de cantos, en la construcción de los muros. Si éstos están formados por una o dos hileras de cantos rodados, se denominarán unimuro o doblemuro, respectivamente.

Dentro de un mismo conjunto puede haber varias técnicas. Así por ejemplo, una estructura habitacional de doble muro puede poseer sus campos de cultivo de unimuro;

c) Forma. Se describirá la forma de la planta de las estructuras, $\mathrm{y}$

d) Tamaño. Cuando es posible proporcionamos el área aproximada de las estructuras. En los otros casos simplemente damos su tamaño relativo (pequeño, mediano o grande).

4. Cronológico. La determinación de la cronología relativa de los conjuntos de estructuras se realizó en base a los tipos cerámicos obtenidos a partir de la recolección superficial de cada uno de ellos.

Diacrónicamente, los tipos diagnósticos son: negro 
engobado, rojo violáceo, colonial (caracterizado por predominio de cerámica corriente y escasez de los tipos anteriores) y reciente (Tipo Río Grande y Toconce). La cronología de este último período ha sido reforzada con datos históricos y etnográficos.

\section{Descripción de los conjuntos de estructuras del yacimiento}

A continuación se describen los conjuntos de estructuras de acuerdo a la nomenclatura dada en Metodología y que aparece en la Lámina 1 (entre pp. 40 y 41).

\section{E1.1.}

\section{Ubicación topográfica: al pie de la loma norte}

Arquitectura y funcionalidad: Corresponde a una casa de yareteros y posee los siguientes recintos: la habitación principal, en buen estado de conservación, con muros de piedra canteada con argamasa, estucada en el interior. Al costado este está el horno y al oeste una gran construcción rectangular de piedra canteada sin argamasa. Frente a ellas y adosados al cerro aparecen varios recintos pequeños de $1 \mathrm{~m}$ de altura como máximo, con una pequeña entrada, que serían corrales para animales pequeños. A unos $10 \mathrm{~m}$ hacia el este comienzan los campos de cultivo de forma circu- lar que son alimentados por un canal de regadío que trae sus aguas del río Puripica y entra al campo por un orificio en la parte inferior del muro. A su costado norte y apegado al cerro aparecen dos habitaciones rectangulares bastante destruidas, y donde se han utilizado piedras sin cantear.

Cronología: Período reciente.

\section{E1.2 (Figura 1)}

Ubicación topográfica: En superficie plana, al borde del actual camino.

Arquitectura y funcionalidad: Corresponde a un conjunto formado por una pirca circular de $14.5 \mathrm{~m}^{2}$ y otra rectangular de $21 \mathrm{~m}^{2}$ adosada a ella en su costado sur. La primera está formada por grandes bloques rodados de unos $60 \mathrm{~cm}$ y puestos en forma vertical, en cambio la segunda alterna dichos bloques con rodados más pequeños, a la vez que posee una puerta de acceso, por el este, constituida por dos bloques verticales. Asociadas al conjunto aparecen cuatro líneas de bloques, bastante destruidos y que pueden haber sido eras de cultivo $\left(110 \mathrm{~m}^{2}\right)$. Probablemente la habitación rectangular es posterior.

Cronología relativa: Tipo cerámico predominante; negro engobado.

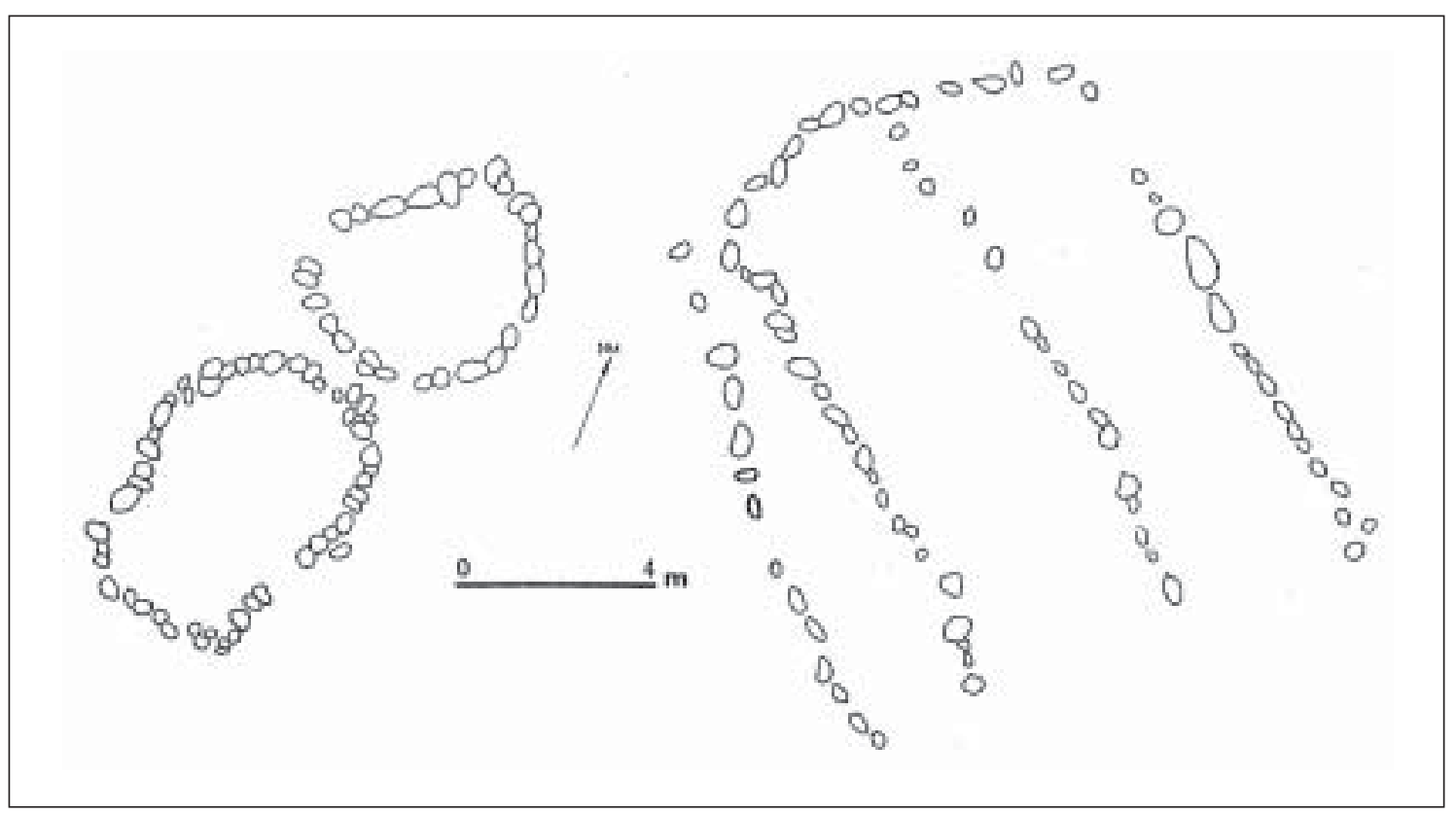

Figura 1. E.1.2. Estructuras habitacionales y campos de cultivos. 


\section{E1.3.}

Ubicación topográfica: En superficie plana.

Arquitectura y funcionalidad: Campo de cultivo rectangular, delimitado por una hilera de cantos rodados puestos en forma vertical y con subdivisiones interiores de rodados más pequeños. En el lado sureste aparece un amontonamiento de piedras producto de la limpieza del campo. $\mathrm{Su}$ asociación con los conjuntos antes descritos no es clara.

Cronología: Predomina el tipo cerámico rojo violáceo.

\section{E1.4 y E1.5.}

Ubicación topográfica: Se encuentra en superficie plana y a pocos metros al este del actual camino.

Arquitectura y funcionalidad: Hipotéticamente los hemos considerado como un conjunto. El primero de ellos es un paralelogramo formado por una hilera de bloques, con subdivisiones internas, muy borradas. El segundo, corresponde a dos recintos semirrectangulares, con muralla doble de bloques puestos verticalmente. Sus áreas son: E1.4 de $2.000 \mathrm{~m}^{2}$ y E1.5 de $72 \mathrm{~m}^{2}$. Este último, dado su tamaño y características, lo suponemos corral.

Cronología: Predominan los tipos cerámicos negro engobado y rojo violáceo respectivamente. ${ }^{1}$

\section{E1.7 int. y ext. (Figura 2)}

Ubicación topográfica: En superficie plana. Por su costado norte, limita con un lecho seco.

Arquitectura y funcionalidad: El E1.7 int. está formado por tres recintos semirrectangulares de $15 \mathrm{y}$ $20 \mathrm{~m}^{2}$, el 1 y 2 , respectivamente, y apoyados en un gran bloque natural. El E.1.7 ext. consta de dos campos de cultivos rectangulares de $300 \mathrm{~m}^{2}$, uno de los cuales posee un canal de regadío interior.

1 Conviene señalar que en todos los casos ha habido reocupaciones coloniales, por lo que en repetidos casos la forma original ha sido modificada o alterada.
Cronología: Predomina la cerámica negro engobada y rojo violácea, respectivamente.

\section{E1.8 (Figura 3)}

Ubicación topográfica: Se encuentra cerca del conjunto anterior, aprovechando una superficie plana.

Arquitectura y funcionalidad: Son tres recintos semirrectagulares con puerta de acceso al lado sureste, de 48,32 y $12 \mathrm{~m}^{2}$, respectivamente. El primero de ellos, se encuentra separado del resto. Se presenta un cuarto recinto, muy destruido, apegado a los últimos.

En clara asociación a éstos aparecen algunas hileras de cantos rodados que formarían el campo de cultivo de aproximadamente $400 \mathrm{~m}^{2}$.

Cronología: Predomina el tipo cerámico rojo violáceo.

\section{E1.9.}

Ubicación topográfica: Se encuentra en el fondo de un lecho seco y ocupa su ladera norte.

Arquitectura y funcionalidad: Son dos estructuras circulares separadas una de la otra $5 \mathrm{~m}$. Poseen un radio de $1 \mathrm{~m}$ y sus muros están compuestos de bloques rodados de 30 a $40 \mathrm{~cm}$ y apoyados en algunos bloques naturales.

Cronología: Producto de la recolección superficial, predominaron los tipos rojo violáceo.

Hemos señalado en el mapa como E1.9.1 a un taller lítico que parece haber sido recogido anteriormente, puesto que sólo se encuentran en él desechos y lascas sin trabajar.

\section{E10.}

Ubicación topográfica: Al pie de la loma sur y junto al actual camino.

Arquitectura y funcionalidad: Corresponde a dos pequeños recintos cuadrangulares construidos con cantos rodados sin argamasa y que son utilizados en la actualidad como paradero de camioneros.

Cronología: reciente. 


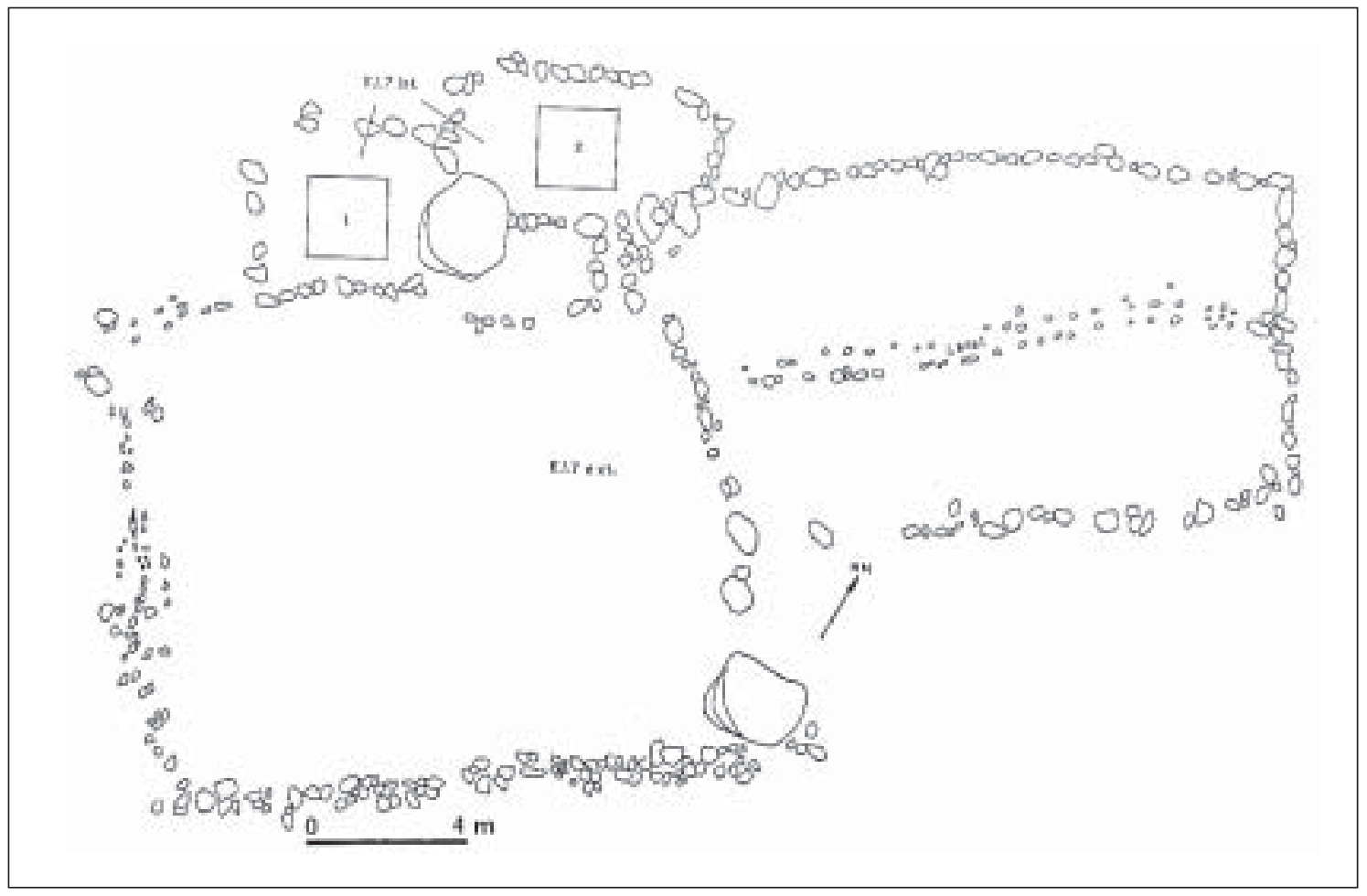

Figura 2. E.1.7 int. Estructura habitacional; E.1.7 ext. Campos de cultivo. Escala 1:100.

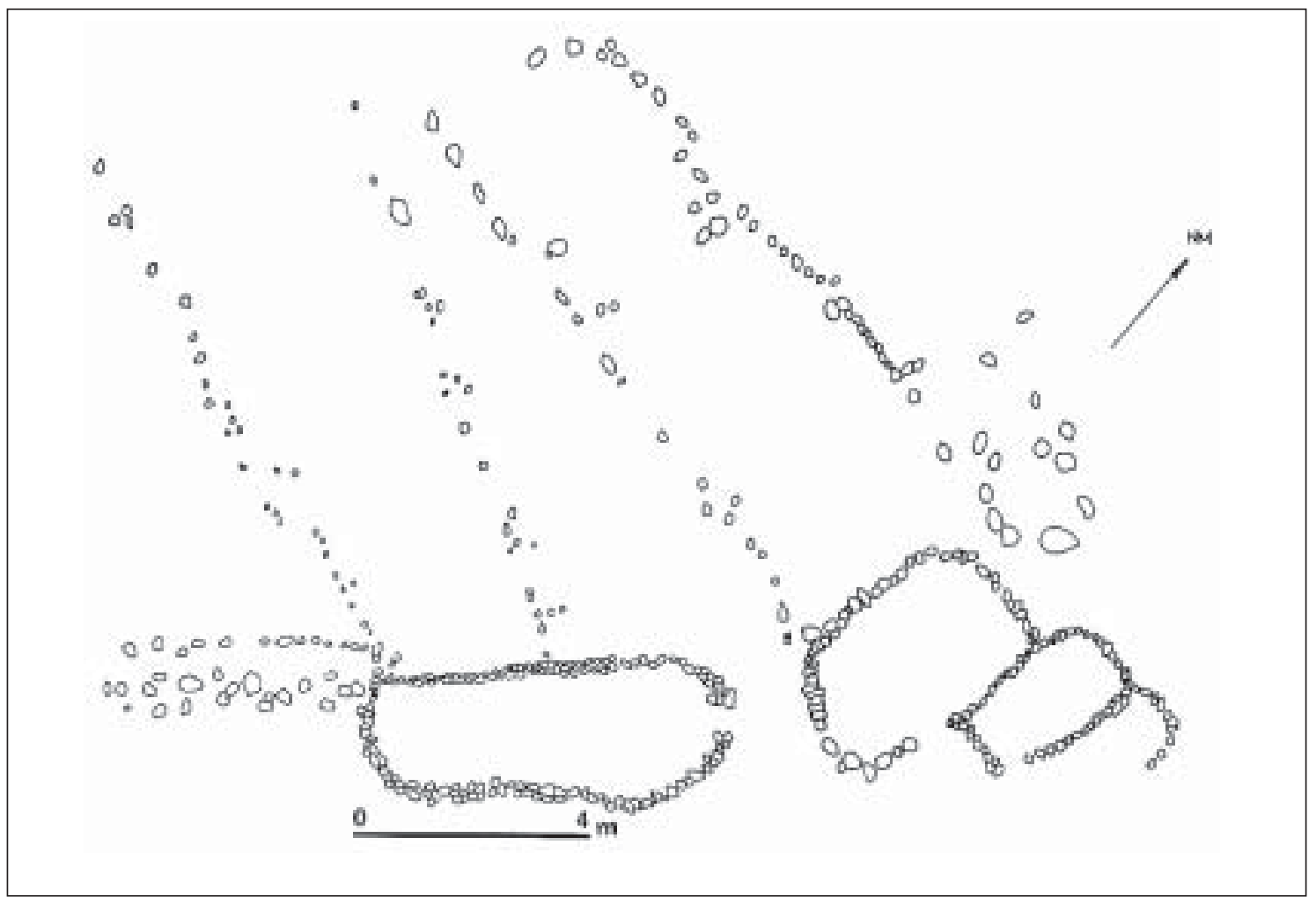

Figura 3. E.1.8 Estructura habitacional y campo de cultivo. Escala 1:100. 


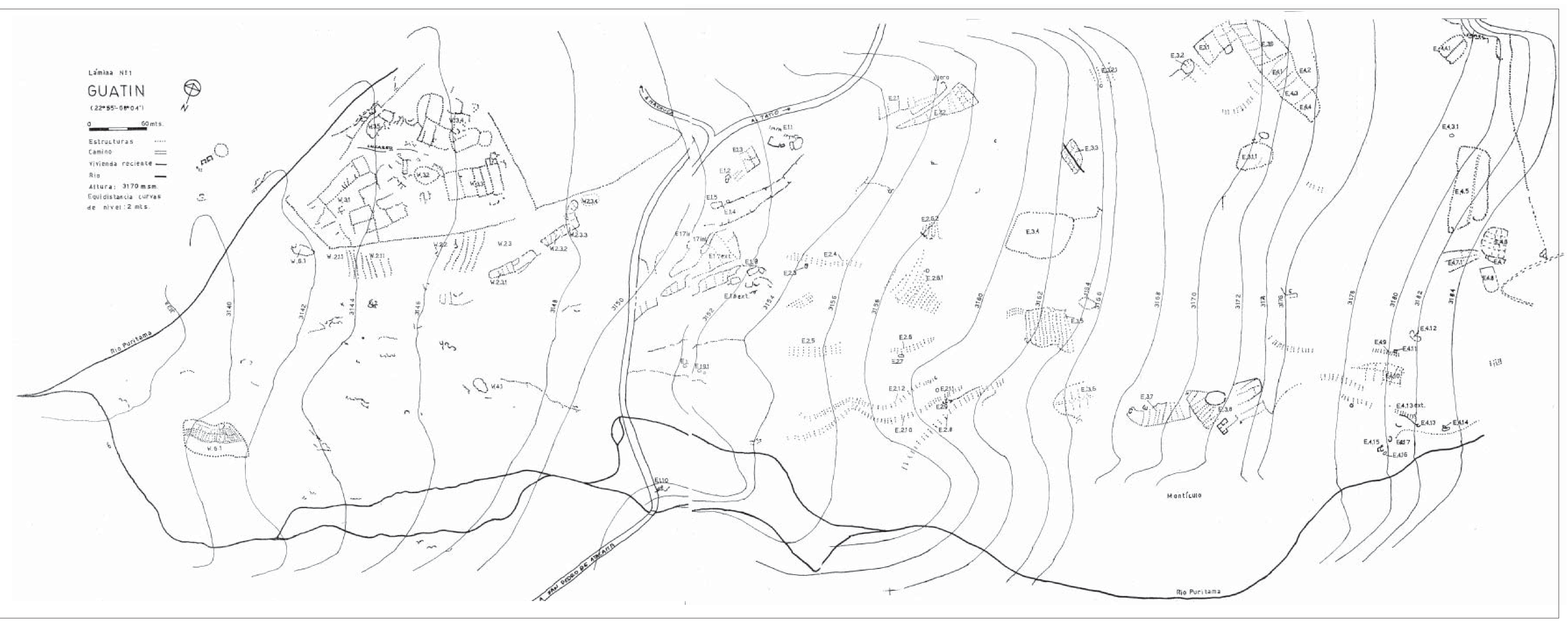


9. E2.1.

Ubicación topográfica: Aprovecha una superficie plana entre la loma norte y un lecho seco por el sur.

Arquitectura y funcionalidad: Campo de cultivo, formado por dos terrazas, la superior apoyada en un andén y la inferior dividida en varios campos, señalados por surcos en la sierra. En su extremo este hay un alero con señales de ocupación. Al borde del lecho pasa un canal de regadío, que probablemente lo alimentaba, pero que continúa hasta desembocar en el campo E1.1 ya descrito. $\mathrm{Su}$ área aproximada es de $700 \mathrm{~m}^{2}$.

Cronología: Tipos cerámicos de superficie: negro engobado y rojo violáceo.

\section{E2.2.}

Ubicación topográfica: A pocos metros al sur de la anterior y aprovecha superficie plana.

Arquitectura y funcionalidad: Campo de cultivo de planta triangular, con divisiones interiores de hileras de cantos rodados dispuestos paralelamente, sin asociación a habitación salvo al alero.

Cronología: Predomina el tipo cerámico rojo violáceo.

\section{E2.3 y E2.4.}

Ubicación topográfica: El campo de cultivo se encuentra en lecho seco.

Arquitectura y funcionalidad: Conjunto formado por una estructura habitacional y su respectivo campo de cultivo. La primera de ellas, E2.3 posee dos recintos, uno circular en el lado sur y otro semirrectangular adosado, en cuya construcción se alternan los bloques con los cantos rodados. Se la ha construido en la ladera del lecho y a $2 \mathrm{~m}$ sobre los campos. Estos poseen subdivisiones de doble y unimuros alternados. El campo adopta una forma alargada, similar a la del lecho que lo contiene, y su área aproximada es de $450 \mathrm{~m}^{2}$.

Cronología: Predominan los tipos cerámicos negro engobado y rojo violáceo.

\section{E2.5, E2.6 y E2.7.}

Ubicación topográfica: Están en lecho seco.

Arquitectura y funcionalidad: Los dos primeros corresponden a campos de cultivo en lecho seco y entre ellos existe un espacio sin utilizar. Sus áreas son 416 y $264 \mathrm{~m}^{2}$, respectivamente. En el costado sur del lecho y aprovechando una superficie de cota más alta está la estructura habitacional pequeña y circular construida con bloques.

Cronología: Cerámica tardía y colonial.

\section{E2.6.1.}

Ubicación topográfica: Aprovecha una superficie plana.

Arquitectura y funcionalidad: Conjunto de una pequeña estructura habitacional de planta rectangular, apoyada en un bloque natural y su correspondiente campo de cultivo de forma triangular formado por hileras paralelas de cantos rodados y alimentado por un canal de regadío interior. $\mathrm{Su}$ área es de $1200 \mathrm{~m}^{2}$.

\section{E2.6.2.}

Ubicación topográfica. Ubicado en superficie plana.

Arquitectura y funcionalidad: Conjunto parecido al anterior formado por estructuras rectangulares, unas de tamaño pequeño, habitacionales, y otras mayores o campos de cultivo. El área de estos últimos es de $300 \mathrm{~m}^{2}$.

\section{E2.8 y E2.9 (Figura 4).}

Ubicación topográfica: Campo de cultivo en lecho seco.

Arquitectura y funcionalidad: Conjunto formado por un campo de cultivo y su correspondiente estructura habitacional. Esta última consta de dos recintos semiovales con el muro interior común, construidos de bloques. Los campos, como en el caso del E2.3 y E2.6, poseen sus eras divididas por una hilera de cantos rodados, unimuro y la siguiente doblemuro y así sucesivamente. Gran importancia adquiere una hilera de piedras que se extiende por el borde sur de los campos y que correspondería al canal de regadío que los alimentaba introduciendo sus aguas a través del doble muro solamente.

Cronología: Predomina el tipo cerámico rojo violáceo. 


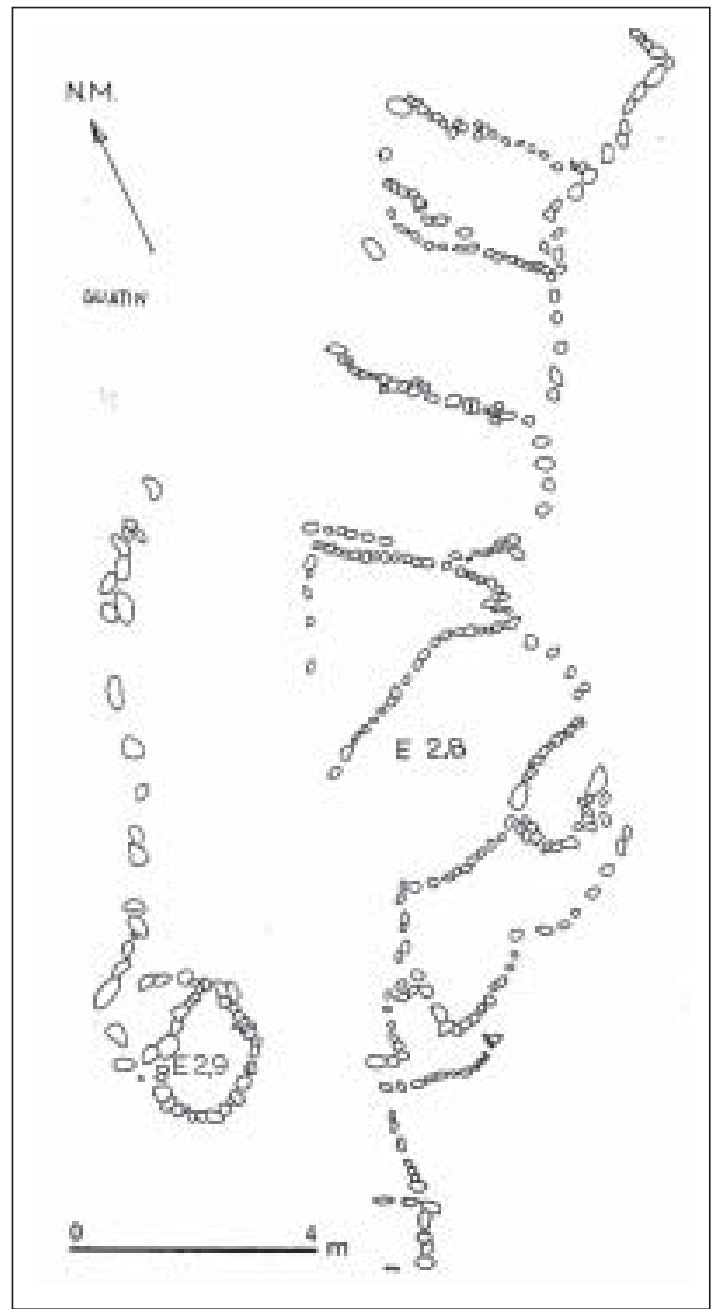

Figura 4. E2.8 Campos de cultivo; E2.9 Estructura habitacional.

16. E2.10, E2.11 y E2.12.

Ubicación topográfica: Campos en lecho seco.

Arquitectura y funcionalidad: Otro conjunto similar al anterior con una estructura habitacional asociada, E2.11, construida con bloques. Algunos metros en dirección oeste existe un taller lítico que ya habría sido recolectado, puesto que sólo quedaban desechos y algunos núcleos y lascas. Los campos de cultivos adoptan la forma de $\mathrm{H}$, debido a que aprovechan los cursos secos de dos esteros que corren paralelos, pero que se desdoblan y topan en la parte central. Su área es de $1400 \mathrm{~m}^{2}$.

Cronología: Predominan los tipos tardíos; rojo violáceos y sus variantes.
17. E3.1, E3.2, E3.9, E4.1, E4.2, E 4.3 y E4.4. y E44.

Ubicación topográfica: En superficie plana.

Arquitectura y funcionalidad: Tentativamente se ha considerado como un conjunto de campos de cultivo. El E3.1 es uno delimitado externamente por bloques en disposición unimuro y con subdivisiones internas de cantos rodados. Por el centro está cruzado por dos hileras paralelas de cantos que corresponderían al canal de regadío. $\mathrm{Su}$ área es de $800 \mathrm{~m}^{2}$.

A pocos metros en dirección oeste se encuentra otra estructura semirrectangular denominada E3.2. El recinto E3.9, delimitado en su exterior por grandes bloques, presenta en el costado sur del muro, un canal de regadío y otro que lo atraviesa por la parte central, a diferencia del E4.1 que lo posee en su costado oeste. El E4.3 presenta un rectángulo pequeño en su extremo sur que correspondería a una habitación. El área ocupada por estos tres últimos campos es de $3000 \mathrm{~m}^{2}$. Hacia el sur aparecen algunas estructuras semicirculares, que hemos denominado E3.1.1 y en sus alrededores existen numerosos bloques y cantos rodados diseminados que habrían formado parte de estructuras habitacionales.

Cronología: La recolección de cerámica superficial entregó escasos tipos diagnósticos, por lo que lo suponemos colonial.

\section{E3.2.1.}

Ubicación topográfica. Estructuras en superficie plana.

Arquitectura y funcionalidad: Dos recintos circulares construidos con cantos rodados unidos por un muro central, asociados a los cuales hay un campo de cultivo delimitado por hileras paralelas de cantos rodados.

\section{E3.3.}

Ubicación topográfica: Estructuras en superficie plana.

Arquitectura y funcionalidad: Campo de cultivo de forma semirrectangular con divisiones interiores y cruzado por un canal de regadío. No está asociado a estructura habitacional. Area $=320 \mathrm{~m}^{2}$.

Cronología: Tipo cerámico predominante: rojo violáceo. 
20. E3.4.

Ubicación topográfica: Estructuras en superficie plana.

Arquitectura y funcionalidad: Es un enorme campo de cultivo sin divisiones interiores, pero aparecen los restos de un canal de regadío que lo alimentaba, introduciéndose por el este. No está asociado a habitación cercana y su área aproximada es de $2400 \mathrm{~m}^{2}$.

Cronología: Tipos cerámicos coloniales o recientes.

\section{E3.5.}

Ubicación topográfica: Estructuras en superficie plana.

Arquitectura y funcionalidad: Campo de cultivo de planta semirrectangular, delimitado externamente por unimuro y con divisiones internas de hileras paralelas de cantos rodados. Su área es de $1750 \mathrm{~m}^{2}$. A escasa distancia hacia el noreste aparece otra estructura oval de tamaño mediano.

Cronología: Tipos cerámicos: negro engobado y rojo violáceo.

\section{E3.6, E3.7 y E3.8.}

Ubicación topográfica: Estructuras en superficie plana, pero al pie de loma.

Arquitectura y funcionalidad: El primero de ellos posee la planta semicircular y divisiones internas, atravesado por un canal de regadío. Su asociación al E3.7 y E3.8 no es clara, puesto que corresponde a campos de cultivo y habitación al pie de loma. Los campos poseen planta irregular con divisiones internas de hileras paralelas de piedra, mientras que la casa posee cuatro recintos rectangulares, construida con piedra canteada. A pocos metros en dirección norte se encuentra un corral de planta oval.

De acuerdo a nuestro informante, Juan Vilca, lugareño, habitaba dicho conjunto una familia que tenía por actividad la agricultura y pastoreo, siendo su abandono reciente.

Cronología: El E3.6 entregó en la recolección algunos fragmentos negro engobado y tipos posteriores. En el E3.7 y E3.8 sólo se presentan tipos recientes.
23. E4.4.1.

Ubicación topográfica: Estructuras en superficie plana.

Arquitectura y funcionalidad: Campos de cultivo de planta semirrectangular de $450 \mathrm{~m}^{2}$ con canal de regadío interior, siendo dudosa su asociación a dos estructuras ovales, ubicadas a pocos metros en dirección noroeste. Presenta cierta semejanza con el campo E3.3.

\section{E4.3.1 y E4.3.}

Ubicación topográfica: Estructuras ubicadas en el extremo este del yacimiento en una superficie plana.

Arquitectura y funcionalidad: El primero, corresponde a dos recintos rectangulares, construidos con técnica de doble muro con cantos rodados medianos. El segundo es un enorme campo de cultivo de $2500 \mathrm{~m}^{2}$, de planta rectangular, y atravesado por un canal de regadío que lo divide por el centro. No posee divisiones internas y en su extremo suroeste existe un pequeño recinto rectangular, que pudo haber sido habitacional.

Cronología: Dada la ausencia de tipos cerámicos negro engobado y rojo violáceo en superficie, atribuimos los fragmentos al Período Colonial.

\section{E4.6, E4.7, E4.7.1 у E4.8.}

Ubicación topográfica: Estructura en superficie plana.

Arquitectura y funcionalidad: Corresponde a campos de cultivos semirrectangulares. El primero posee divisiones internas de pequeños cantos rodados y se caracteriza por tener en su extremo suroeste, un pequeño recinto rectangular con puerta de acceso sur, señalada por dos bloques verticales. Las áreas de los campos es de 600, 300 y $180 \mathrm{~m}^{2}$.

Cronología: Predominan los tipos tardíos como el rojo violáceo.

\section{E4.12.}

Ubicación topográfica: Estructuras en superficie plana.

Arquitectura y funcionalidad: Recinto de planta irregular, con división interior y que por arrojar bastante cerámica superficial, suponemos habitacional. 
Cronología: De los 457 fragmentos cerámicos superficiales predomina el rojo violáceo, café pulido y reciente.

\section{E4.9 y E4.11.}

Ubicación topográfica: Campos en lecho seco.

Arquitectura y funcionalidad: Campos de cultivo en lecho seco y que al igual que el E2.5 y E2.6 se interrumpen en ciertos trechos y continúan posteriormente. Están asociados a habitación.

Cronología: Predomina el tipo cerámico rojo violáceo.

\section{E4.10.}

Ubicación topográfica: Campos construidos en una superficie plana entre dos lechos actualmente secos.

Arquitectura y funcionalidad: Campo de cultivo de planta rectangular con divisiones internas de $640 \mathrm{~m}^{2}$ aprox.

Cronología: Predominaron en la recolección superficial los tipos cerámicos coloniales.

29. E4.13 int. y ext. (Figura 5).

Ubicación topográfica: Campos de cultivo en lechos secos.

Arquitectura y funcionalidad: Conjunto formado por una estructura habitacional (fue excavada) construida originalmente por dos o tres recintos semicirculares, apoyados en un bloque natural y que posteriormente se ampliaron a cuatro para utilizarlos como corral. Asociados a éstas aparecen los campos de cultivo en lecho seco de $210 \mathrm{~m}^{2}$. No se encuentra en estos campos la alternancia de doble y simple muro.

Cronología: Se encontró bastante cerámica tipo negro engobado y tipos posteriores.

\section{E4.14}

Ubicación topográfica: Estructura en superficie plana.

Arquitectura y funcionalidad: Son dos o tres recintos semicirculares, uno de los cuales es de mayor tamaño que el resto y que serían la habitación y su corral.

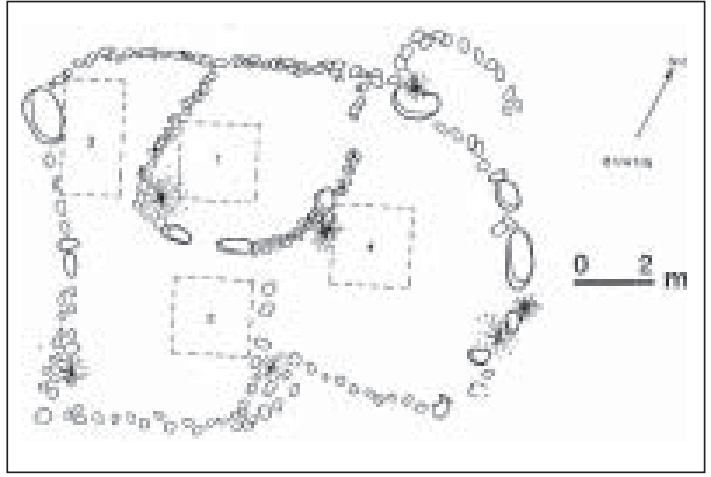

Figura 5. E4.13 int. Estructura habitacional.

Cronología: Posee en superficie los tipos cerámicos negro engobado y rojo violáceo.

31. E4.15 y E4.16.

Ubicación topográfica: Estructura en superficie plana.

Arquitectura y funcionalidad: Recinto de planta rectangular, bien conservada y construida por bloques de piedra canteada. El E4.16 está muy destruido y lo suponemos como el corral asociado.

Cronología: Dada la presencia de todos los tipos cerámicos, suponemos que la estructura primitiva fue reutilizada en los períodos siguientes inclusive el actual.

A continuación se describen las estructuras y conjuntos del sector oeste del camino. El sector W2 no presenta estructuras debido a que fueron destruidas por la instalación de un campamento de vialidad (Figura 6).

32. W2.1.2, W2.1 y W2.2.

Ubicación topográfica: en superficie plana.

Arquitectura y funcionalidad: Campos de planta rectangular formados por hileras de cantos rodados paralelos. Entre una y otra hay un espacio vacío. Las áreas del W2.12 y W2.2 son 900 y $1000 \mathrm{~m}^{2}$, respectivamente.

Cronología: Se encontró cerámica negro engobada y roja violácea. 


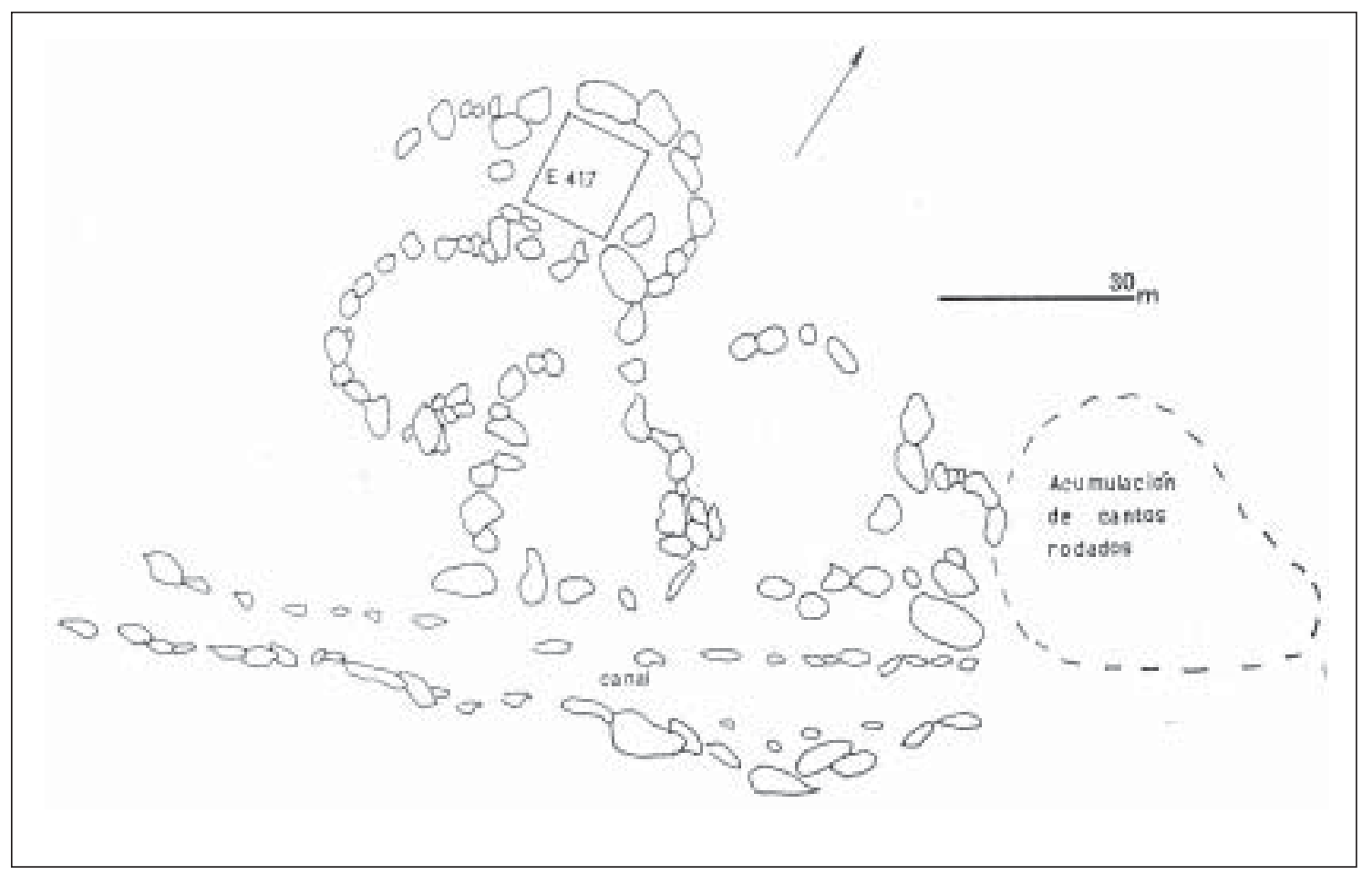

Figura 6. E4.17 Estructuras (?).

33. W2.3.1, W2.3.2 y W2.3.3.

Ubicación topográfica: Estructuras en superficie plana.

Arquitectura y funcionalidad: El primero de ellos posee $470 \mathrm{~m}^{2}$, planta rectangular y es atravesado de norte a sur por dos canales interiores. Hacia la parte norte del campo aparece una habitación de forma semirrectangular construida con bloques de un tamaño de $40 \mathrm{~cm}$ promedio. Al costado hay un canal formado por cantos rociados. El segundo campo de $400 \mathrm{~m}^{2}$ tiende a lo rectangular y posee divisiones internas, mientras que el tercero posee la planta irregular.

Cronología: Fueron construidos en el Tardío y reutilizados en el Colonial.

\section{W4.1.}

Ubicación topográfica: Estructura en superficie plana.

Arquitectura y funcionalidad: Recinto semicircular construido por bloques de $50 \mathrm{~cm}$. A corta distancia se ubica una excavación bastante grande que, de acuerdo a nuestros informantes, fue realizada por buscadores de oro. No apareció cerámica superficial.

\section{W5.1.}

Ubicación topográfica: Estructura en superficie plana.

Arquitectura y funcionalidad: Pequeñas estructuras muy destruidas con tendencia a planta circular, ubicadas al costado de lechos secos. En este sector, uno de los de menor cota del yacimiento y por tanto más afectado por los aluviones, se encuentran alineamientos de bloques y rodados, que atribuimos a la acción de éstos.

Cronología: En base a la recolección superficial de cerámica lo suponemos colonial.

\section{W6.1.}

Ubicación topográfica: Campo en superficie plana.

Arquitectura y funcionalidad: Corresponde a un enorme campo de cultivo de planta semirrectangular delimitada exteriormente por bloques y atravesada por un canal de regadío que lo divide en 


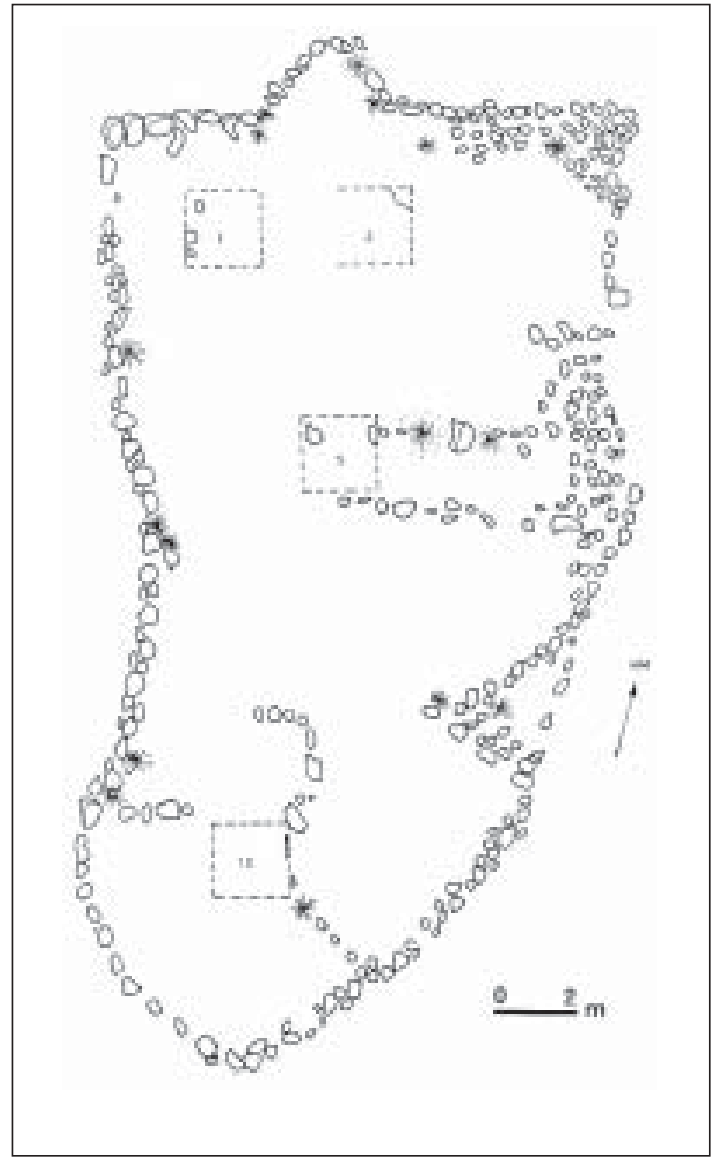

Figura 7. W3.12 Campos de cultivos. una mitad norte con divisiones interiores paralelas de hileras de cantos rodados y la otra despejada. Lo asemejamos a E3.3 y E4.3.1. El área es de $2000 \mathrm{~m}^{2}$.

Cronología: Predomina la cerámica colonial.

Todas las que vienen a continuación poseen en común su ubicación topográfica en superficies planas.

\section{W6.2.}

Arquitectura y funcionalidad: Recinto semioval construido con bloques y sin divisiones interiores, por lo que sería corral.

\section{W3.1.}

Arquitectura y funcionalidad: Campos de cultivo de planta rectangular formando una aglomeración con probable asociación a estructuras habitacionales de planta rectangular y semicircular. En su construcción se han utilizado los cantos rodados y a sus costados hay acumulación de éstos, producto de la limpieza del campo. No poseen divisiones interiores. Area total $=5400 \mathrm{~m}^{2}$.

39. W3.2.

Arquitectura y funcionalidad: Estructura oval de tamaño mediano, que suponemos corral.

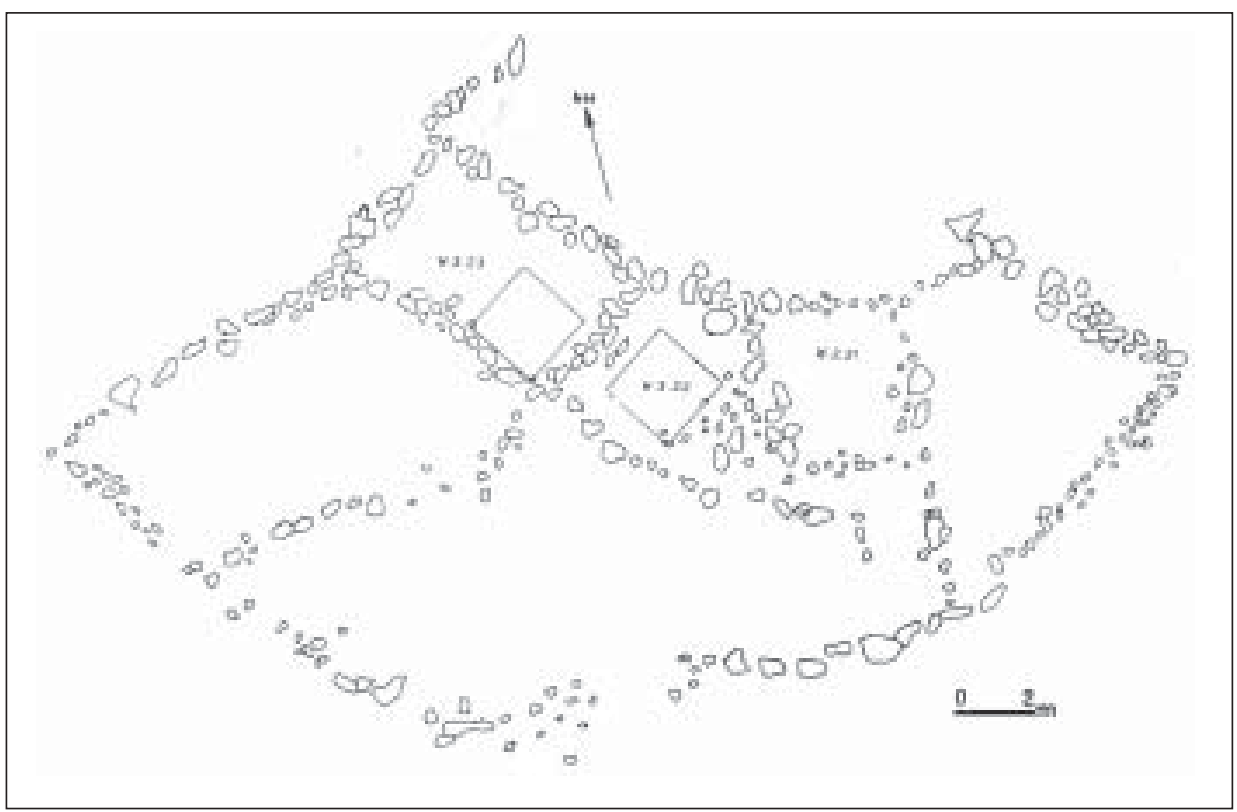

Figura 8. W3.22 y W3.23 Campos de cultivo y estructuras habitacionales. 
40. W3.3. (Figura 9).

Arquitectura y funcionalidad: Campo de cultivo de planta rectangular, subdividido en 5 segmentos. Su área es de $1680 \mathrm{~m}^{2}$ y está asociado a varios recintos habitacionales de planta semicircular en la que se utilizaron bloques para la construcción de los muros.

\section{W3.4.}

Arquitectura y funcionalidad: Campos semirrectangulares y ovales contiguos, ubicados en superficie plana, tamaño mediano, con o sin divisiones internas y asociado a habitaciones. Su área es de $3100 \mathrm{~m}^{2}$.

\section{W3.5.}

Arquitectura y funcionalidad: Conjunto de estructuras muy similares a la anterior.

El sector W3, delimitado externamente por un muro fue estudiado en forma bastante detallada, encontrándose lo siguiente:

67 unimuros, caracterizados por baja altura, utilización de cantos rodados pequeños, puestos en forma vertical a horizontal indistintamente y que por lo general corresponden a campos de cultivo.

61 doblemuros, de mayor altura, utilización de bloques, puestos preferentemente en posición ver-

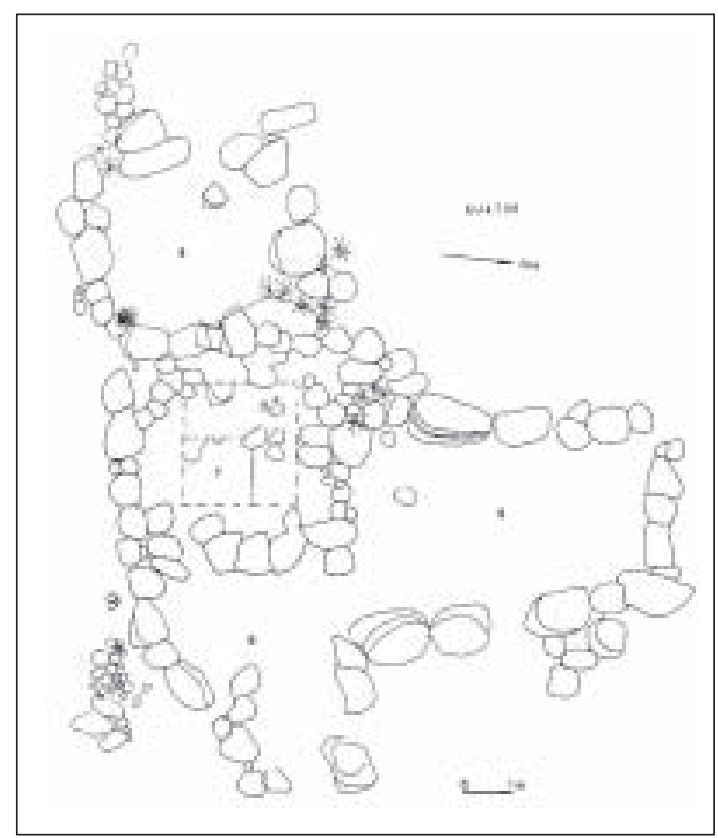

Figura 9. W3.3. 6-7-8-9 Estructuras habitacionales. tical y que corresponden a estructuras habitacionales y corrales.

Se encontraron sólo siete estructuras con triple muro.

El muro exterior, que encierra al sector W3, posee doble muro y seis hileras de piedra superpuestas. Las tres inferiores, en su mayoría son puestas horizontalmente, en cambio el resto, en forma desordenada, lo que indicaría que fue construida en dos etapas.

Cronología: La recolección superficial de la cerámica proporcionó todos los tipos ya descritos; negro pulido y negro engobado, rojo violáceo y colonial. En base a excavaciones parece ser que el primero de ellos llega por arrastre y que las primeras estructuras son construidas durante el Tardío y reutilizadas en el Colonial. Por el centro del sector en descripción hay evidencias de un canal de regadío, que se extiende de este a oeste.

\section{Categoría de conjuntos}

Los conjuntos de estructuras descritos se han clasificado en categorías en base a los criterios de ubicación topográfica, funcionalidad, arquitectura y cronología. El primero de ellos permitió agruparlos en tres categorías diferenciadas, a saber: asentamientos al pie de lomas, en lecho seco y en superficies planas. El resto de los criterios permitió distinguir las variantes dentro de cada categoría:

Categoría 1: Asentamiento al pie de loma.

a) Desde un punto de vista topográfico, esta ocupación tiende a los espacios planos al pie de las lomas que delimitan el yacimiento en estudio. En uno de los casos, las estructuras ocupan la ladera;

b) y c) Desde un punto de vista arquitectónico y funcional se distinguen:

- Recintos habitacionales de dos o tres cuartos, de planta rectangular o cuadrangular, muros construidos con cantos rodados y bloques canteados unidos con argamasa de barro y que en su interior pueden estar estucados. A corta distancia se encuentra el horno.

- El corral mayor para animales grandes y a veces uno o más corrales pequeños para anima- 
les menores (chinchilla, etc.). El primero de ellos siempre posee forma circular con una pequeña puerta de acceso y en la que se cobijaban ovejas, cabras y llamos.

- Los campos de cultivo. Se encuentran a pocos metros de las estructuras anteriores y están delimitados por muros de rodados sin cantear. En su interior poseen subdivisiones rectangulares, en algunos casos de hileras de piedra y en otros simplemente acequias. La alimentación de agua se efectúa por canales que se introducen al campo por un orificio en la base del muro, y siempre provienen del río Puripica, nunca del Puritama, por su alto contenido de boro.

- Bodegas: Sólo en el caso del E1.1 se encontró una gran bodega de planta rectangular, que sirvió para almacenar llareta.

Los conjuntos que incluimos dentro de esta categoría son los siguientes: E1.1, E3.6, E3.7, E3.8, E4.15, E4.16, E1.10 y W1.

d) Cronología: En base a fragmentos de cerámica superficial, datos históricos y etnográficos, situamos a esta ocupación entre el 1880 y 1950 DC. ${ }^{2}$

\section{Categoría 2: Campos de cultivo en lechos secos.}

a) Ubicación topográfica: Siempre los campos son construidos en el fondo de los lechos secos de estero o aluviones, mientras que la estructura habitacional asociada lo está en la ceja del lecho. Quedando así a unos $2 \mathrm{~m}$ sobre éste, con la doble ventaja de poseer así un dominio visual del campos y evitar la humedad del lecho.

b) y c) Arquitectura y funcionalidad: Se caracterizan por ser campos de cultivo alargados, puesto que adoptan la forma del lecho que las contiene y que poseen divisiones uni y doble muro alternados, que se extienden perpendicularmente a la dirección del campo. Han ocupado en su construcción los mismos cantos rodados del lecho, ya que no se ven grandes acumulaciones de éstos a

2 Se ha considerado a 1880, como comienzo del Período Reciente, puesto que hacia aquellos años se produce la Guerra del Pacífico (1879), con amplias repercusiones en el área, y en 1884, una gran avenida destruye Guatin (Risopatrón 1924; 376). los costados. En uno de los bordes se pudo observar un canal de regadío que trae las aguas del Puripica y se introduce al campo por la doble línea de piedras (doblemuro). Aunque el lecho posee desnivel, no se ha utilizado el sistema de terrazas.

Las probables casas asociadas se ubican en uno de los bordes (preferentemente sur) del campo y constan de dos recintos adosados, uno semicircular y el otro rectangular. Generalmente aprovechan un bloque grande natural en el cual apoyar uno de sus muros. Ninguno posee en asociación corrales, por lo que serían principalmente agricultores.

En lo que respecta a su distribución en el área, cabe destacar que sólo ocupan el sector este y preferentemente los lechos que corren por el lado sur de éste.

Los conjuntos que pertenecen a esta categoría son: E2.3, E2.4, E2.5, E2.6, E2.7, E2.11, E2.12, E4.9, E4.11 y finalmente E4.13 int. y ext.

d) Cronología: Predominaron en la recolección superficial de cerámica los tipos tardíos rojo violáceo y sus variantes. Sin embargo, las estructuras excavadas dieron un primer estrato negro engobado.

\section{Categoría 3: Estructuras en superficie plana.}

Dada la gran variedad de conjuntos que integran esta categoría, se hace indispensable dividirlos en base al criterio cronológico.

a) Ocupación del negro engobado

Presenta gran dificultad en su reconstrucción, debido a que sus estructuras fueron reutilizadas en períodos posteriores. Probablemente corresponden a habitaciones semicirculares apoyadas en un bloque natural. Sus muros han sido construidos con cantos rodados y bloques en posición vertical, al igual que sus campos de cultivo, que tienden a una forma rectangular.

\section{b) Ocupación roja violácea (Tardío)}

Además de la descrita en Categoría 2, existen otras modalidades de asentamiento durante este período. 
b1) Ubicación topográfica: Ya se dijo que se ubican en superficies planas, pero aprovechan toda la superficie hasta llegar al borde mismo del lecho, por lo que al menos, por un lado, adoptan su forma. Su dispersión en el área se restringe al sector este 1 y 2, o sea, a la parte central del área en estudio.

Arquitectura y funcionalidad: Corresponden a campos de cultivo asociados a estructuras habitacionales. En los casos E2.1 y E2.2, los campos están asociados a alero. Se intensifica el regadío de los campos por medio de canales o acequias.

Las habitaciones constan de dos recintos, uno de los cuales es circular y el otro semirrectangular. Los recintos E1.5 y E1.8 serían corrales.

En ninguno de los casos estudiados se ha utilizado la piedra canteada. Pertenecen a este grupo las siguientes estructuras: E1.4, E1.5, E1.7 ext. e int. E1.8, E2.1 y E2.2.

b.2) Ubicación topográfica: Además de ser erigidas en superficie plana, nunca llegan hasta el borde de los lechos.

Arquitectura y funcionalidad: Son campos de planta rectangular con canal de regadío interior y en algunos casos poseen la habitación dentro del campo. El campo E3.3 poseen divisiones internas y un canal de regadío que lo cruza por el centro. El área cultivada aumenta considerablemente al igual que se desarrollan nuevas técnicas hidroagrícolas.

Su dispersión dentro del área se centra en el sector E4, en el extremo este, y son los conjuntos E4.6, E4.7, E4.7.1, E4.8 y E4.12.

c) Ocupación colonial

c.1) Ubicación topográfica: Campos en superficie plana que limitan por su costado norte con un lecho seco.

Arquitectura y funcionalidad: Campos de cultivo de tamaño grande de planta irregular, subdivisiones interiores y canales de regadío por el borde del muro exterior y por el centro del campo. Un pequeño rectángulo dentro del recinto E4.3 sería habitacional, mientras que otro de tamaño mediano al costado sur del E3.1, el corral. El resto de los recintos corresponden al E3.1, E3.9, E3.1.1., E4.1 y E4.2.

c.2) Ubicación topográfica: Se han construido en superficies planas, lejos de lechos, y su dispersión alcanza los extremos del área.

Arquitectura y funcionalidad: Los conjuntos W6.1, E4.4.1 y E4.3 poseen en común el gran tamaño, la planta semirrectangular y un canal de regadío que los cruza a lo largo dividiéndolo en dos partes. Sólo el E4.3 posee en clara asociación un pequeño recinto rectangular en su interior, con función habitacional.

El E4.4.1 es un campo alimentado por un canal de regadío excavado en la ladera de las lomas este y que, a través de un complicado sistema, trae sus aguas del Puripica. Pertenecen además a esta ocupación el recinto W6.2.

Las categorías: Inferencias socioeconómicas del poblamiento y cronología relativa.

Hemos intentado inferir algunas características del sistema socioeconómico de los grupos humanos que ocuparon los recintos que ya hemos agrupado en categorías, centrándonos en las actividades agrícolas y ganaderas de autosuficiencia y en las de tipo comercial, entendiendo por éstas las que implican intercambio y contacto con otros centros.

Por carecer de fechaciones radiocarbónicas absolutas, la cronología es de tipo relativa basada fundamentalmente en la clasificación y tipología de la cerámica superficial (ver La cerámica de Guatin, de Serracino, en este volumen). Aunque en la mayoría de las estructuras y recintos aparecen todas las variantes y tipos de cerámica, para efectos de la cronología hemos considerado como tipos diagnósticos a los primeros de la secuencia cerámica. La secuencia de los tipos negro engobado, rojo violáceo, colonial y reciente ha sido comprobada en Guatin, por medio de algunas excavaciones estratigráficas.

Así, por ejemplo, si un conjunto de estructuras presentó en la recolección de cerámica superficial los tipos negro engobado, rojo violáceo y reciente supondremos que dicho conjunto fue construido durante la ocupación negro engobado y reutilizado por las siguientes. Estas suposiciones 
deberán ser confirmadas en el futuro por excavaciones estratigráficas.

\section{Categoría 1:}

Este poblamiento posee en común la tendencia a ocupar las superficies planas al pie de las lomas que circundan el área en estudio, protegiéndose así de las inclemencias del tiempo, vientos, variaciones térmicas, quizás de los aluviones y contando con un dominio visual de dicha área.

Cada conjunto de esta categoría parece haber tenido su propia actividad. Los habitantes del recinto E1.1 se dedicaron preferentemente a la búsqueda y almacenaje de llareta, que se puede evidenciar por la gran bodega rectangular ubicada al costado oeste de la casa habitación. Además poseen corrales pequeños, probablemente para crianza de chinchillas, de alto valor comercial, y campos de cultivo. Por lo tanto, corresponden estos restos a una familia que tenía por actividades las destinadas al autoabastecimiento en base a los productos agrícolas y la comercialización de la llareta (combustible), y chinchillas, en los centros urbanos más cercanos (San Pedro de Atacama y Calama).

El conjunto E3.7 y E3.8 presenta campos de cultivo, un gran corral y la casa de tres recintos, que indicaría que sus ocupantes desarrollaron principalmente actividades agropecuarias de autosuficiencia, pero en el caso de producirse un excedente, lo habrían comercializado.

Los habitantes del recinto W1 por sólo poseer un corral asociado a su casa de dos recintos, suponemos como actividad principal el pastoreo de ovejas, llamos y cabras. Una estancia similar la encontramos representada por el conjunto E4.15 y E4.16. Finalmente los dos recintos E1.10, ubicados al borde del camino de San Pedro al Tatio, son utilizados como refugio y paradero de camioneros.

De esta categoría se pueden inferir los siguientes puntos de acuerdo a un criterio selectivo:

a) Actividades agropecuarias destinadas al autoabastecimiento que en algunos casos deriva en excedentes;

b) Actividades comerciales o de intercambio, determinadas por la caza y crianza de chinchilla, llareta, y por los excedentes mencionados en a).
Cronología relativa: En todos los recintos hemos encontrado cerámica reciente Tipo Río Grande y Toconce, por lo que podemos situar este poblamiento en el período reciente comprendido entre 1880 y 1950 , aproximadamente. Su ubicación temporal no sólo la hemos realizado en base a asociación cerámica sino también con datos etnográficos e históricos.

\section{Categoría 2: Campos de cultivo en lecho seco.}

Conjunto que consiste en la asociación de estructuras habitacionales pequeñas con campos de cultivo construidos en el fondo de un lecho seco de estero, alimentados por un canal de regadío, que fluye a un costado de éste y se introduce al campo por canales secundarios. Este patrón se repite seis veces y aparece únicamente en el lado este del área. Sólo el conjunto E4.13 que parecía alejarse del patrón, puesto que su estructura habitacional poseía cuatro recintos, al ser excavado confirmó la modalidad de dos recintos adosados, uno en forma circular y otro semirrectangular. Los otros dos corresponden a un agregado posterior, que probablemente se usó como corral, debido a una gruesa costra de guano, que había a escasos centímetros bajo la superficie y a la escasez de cerámica. La excavación también confirmó la funcionalidad de los recintos habitacionales, puesto que en ellos se encontraron varios fogones y gran cantidad de fragmentos cerámicos y restos óseos.

En base a las áreas calculadas podemos decir que dichas familias requerían de aproximadamente $400 \mathrm{~m}^{2}$ de superficie cultivada para su sustento. El no estar asociados a corrales implica que su principal actividad era la agricultura, complementada quizás con la caza, puesto que cerca de una se encontraron los restos de un taller lítico. Creemos en todo caso que son ocupaciones agrícolas temporales del área, dada la ausencia de cementerios y la escasez de restos culturales, salvo escasos fragmentos de cerámica. Por otro lado, dadas las condiciones climáticas y la altura de Guatin, las actividades agrícolas se concentran en ciertas estaciones del año y sólo es posible aclimatar una escasa variedad de cultígenos.

Si consideramos que durante el período de máxima ocupación de este patrón agrícola familiar, el que estaba constituido por cuatro a seis individuos, la población de Guatin alcanzó entre 24 y 36 personas. 
Cronología relativa: El estudio de la cerámica superficial de los recintos habitacionales y de los campos de cultivo pertenecientes a este patrón de ocupación, entregó un predominio del tipo rojo violáceo (ocupación tardía) y una reocupación especialmente de las estructuras habitacionales durante el Período Colonial. El conjunto E4.13 int. fue excavado y en el estrato inferior apareció cerámica tipo negro engobado y luego el rojo violáceo, lo que nos hace pensar en que esta modalidad comienza a ser introducida por el negro engobado alrededor del 1050 DC. pero alcanza su máximo desarrollo durante el rojo violáceo. Durante el Período Colonial, comienza a ser abandonado, y en el reciente ya no es utilizado.

\section{Categoría 3: Ocupación en superficie plana.}

Poseen en común el aprovechamiento de superficies planas $\mathrm{y}$, por ende, los campos requieren de regadío artificial.

Dada la variedad de conjuntos, en la subdivisión se utiliza el criterio cronológico:

a) Ocupación negro engobada. Su interpretación es difícil dado el mal estado de conservación de las estructuras y la reutilización de que fueron objeto. Sin embargo, es posible decir que tenían por principal actividad la agricultura no alcanzando ésta gran desarrollo.

b) Ocupación rojo violácea: Se distinguen dos variantes en la ocupación de las superficies planas. La primera se caracteriza por campos de tamaño mediano, asociada a corrales y habitaciones, que nos indicaría que su actividad era agropecuaria y de carácter autosuficiente. El regadío se efectúa por medio de acequias que traen sus aguas del río Puripica.

En la segunda variante el tamaño de los campos varía, y no llegan al borde de los lechos. A menudo posee la habitación dentro del campo y las técnicas de construcción de canales experimentan un notorio desarrollo.

Por ser la habitación de un cuarto y estar dentro del campo, puede suponerse que su actividad principal era agrícola familiar. El gran tamaño de éstos y el escaso énfasis dado a la ganadería permiten suponer que el excedente de los primeros se destinaba al intercambio con pastores, complementando así la dieta. c) Colonial: Se distinguen dos casos:

c.1) Grandes campos de cultivo asociados a pequeñas habitaciones, con gran desarrollo en las técnicas de construcción de los campos y canales que permite suponer un poblamiento familiar con actividades agrícolas tendientes a obtener un excedente que comerciar con las urbes cercanas, especialmente San Pedro de Atacama. Poseerían corrales que indicarían actividades ganaderas complementarias.

c.2) Son grandes campos aislados y dispersos por toda el área y que poseen un sistema de regadío muy desarrollado. Incluso se construye un dique aguas arriba del Puripica, del cual se originan varios canales. Probablemente corresponden a una agricultura de especialización, con introducción de nuevas especies cultígenas, que requieren de mayor cuidado y regadío.

Aunque suponemos que las actividades pastoriles se incrementan, no hemos identificado los corrales. Podrían corresponder a algunas estructurales ovales muy derruidas que se encuentran en sus alrededores.

\section{Correlaciones con otros yacimientos del Norte Grande}

Son escasos los trabajos que han realizado estudios específicos de las estructuras en la zona. Por otro lado, siempre se ha tendido a describir las aldeas y poblados fortificados y escasamente a las ocupaciones agrícolas de carácter disperso. Cabe destacar que como conjunto ninguno de los poblados o asentamientos que se describirán comparten el sistema y características de Guatin; sin embargo, para evitar un inoficioso listado de diferencias, me limitaré a mencionar algunos elementos especialmente arquitectónicos que se presentan en otros yacimientos y guardan relación con Guatin.

Latcham (1938: 80) se refiere a las habitaciones atacameñas del siglo X DC caracterizándolas por poseer los muros bajos, sin puertas ni ventanas y tampoco nichos ni alacenas. En la época siguiente, la chincha-atacameña (1100-1350 DC) los muros se elevan, introducen la puerta de acceso y a menudo ventanas. Aparecen los nichos y alacenas en su interior y la agrupación puede dividirse en grupos unidos o independientes y las aisladas del 
resto que se diseminaban por los campos, cada cual con su predio y donde siempre se utiliza la piedra. Finalmente, se refiere a un campo de cultivo en los alrededores de Vilama, de planta rectangular de 100 x 600 m, y subdividido en hileras y canchas, alimentado por un canal de regadío con muro de barro. Según esta clasificación, las estructuras de Guatin no corresponden a ninguno de los dos períodos, puesto que poseen puerta de acceso pero los muros bajos, carecen de ventanas, nichos y alacenas o habría que incluirlas en su segundo período, pero destacando que se mantienen modalidades del poblamiento anterior y que implicarían que en Guatin los patrones arquitectónicos evolucionan más lentamente que en la urbe. Nos inclinamos por una tercera solución, que plantea que la clasificación del autor es muy general y no se cumple en casos particulares como el de Guatin.

Mostny (1949: 125 y sigs.) realiza un estudio bastante completo de las "ciudades atacameñas" una de las cuales, Quitor, cerca de San Pedro de Atacama, posee estructuras aisladas, que varían en la forma de la planta desde lo rectangular a lo irregular, pasando por la redonda y semicircular, a las que se entra por una puerta formada por "dos grandes piedras paradas... o por piedras canteadas superpuestas". Algunas de estas características arquitectónicas las encontramos en Guatin, pero lo que sería "casi universal" (de las ocupaciones atacameñas) del empleo de argamasa y la forma básica rectangular con puertas" no lo es tanto en la localidad en estudio.

Además, dicha autora (1971: 271 y sigs.) ha realizado importantes trabajos arqueológicos en la subárea de Guatacondo, encontrando varias aldeas que abarcan todo el Período Agroalfarero, que parecen no tener relación directa con el área de San Pedro de Atacama.

Le Paige, que ha estudiado durante años la zona de San Pedro de Atacama piensa que las estructuras de Guatin son tardías (comunicación personal). Le Paige (1957-58, láminas, 1963: 82-83, 1964, láminas) presenta algunos planos de las estructuras de algunos poblados y asentamientos, pero en su conjunto ninguno comparte las características de Guatin. La única semejanza se presenta en el material utilizado: la piedra.
Núñez (1972: 13-16) hace un estudio de los cambios de asentamientos en la parte inferior de la quebrada de Tarapacá que corresponden a cotas menores que las de Guatin y que implican otros mecanismos de adaptación al medio, pasando el canal de regadío a ser "la clave para consolidar la supervivencia de densas comunidades" tardías, que, concentradas en aldeas, poseen planta rectangular o cuadrangular con divisiones internas y técnica de doble pared. Continúa su análisis para los asentamientos histórico-españoles. Sin embargo, las modalidades en los asentamientos de la quebrada de Tarapacá presentan más diferencias que semejanzas con aquellas de Guatin, y la correlación se ve dificultada, puesto que los factores que explican dichos asentamientos corresponden a realidades diferentes.

Niemeyer (1972-3: 115 y sigs.) analiza algunos padrones de poblamiento del Período Agrícola Tardío de la quebrada de Camarones, en la que, al igual que en Guatin, el "dominio de la técnica de irrigación artificial permite un mayor aprovechamiento de la tierra y aumento demográfico". Nuevamente se trata de la descripción de aldeas fortificadas que poseen en común la posición estratégica, pero que se diferencian en que algunas poseen la planta de los recintos rectangular con técnica de dos hileras y en las otras es circular o elíptica con muros de piedra. Ambos tipos de aldea poseen similares fechaciones radiocarbónicas (1270 y 1235), lo que las hace contemporáneas e indica un contacto por parte de unos con el litoral, y por los otros, con el altiplano y que en último término explicaría la presencia de fortificaciones debido a acciones bélicas entre ambas.

Durante la dominación incaica, los campesinos utilizaban las habitaciones circulares reservándose las rectangulares para casos especiales. Agregan los autores que en Camarones Sur aparecen recintos de planta rectangular y recintos circulares o elípticos y que están dispuestos en forma contigua con doble muros comunes. Lo mismo acontece en Chibaljaya-1 y 2, Quiguatama-2 y Saguara. En este último, hay campos de cultivo en forma de andenes o "eras alargadas delimitadas a valle por muros de piedra" y alimentados mediante canales. Esto último es particularmente interesante, puesto que se relacionarían con la ocupación en lechos secos de Guatin, con parecidas características. 
Sin embargo, salvo algunos rasgos arquitectónicos específicos, la correlación con el área en estudio es muy tenue, puesto que corresponden a patrones de poblamiento diferentes.

Resumiendo, podemos afirmar que en base a los trabajos analizados no se han descrito hasta el momento para el Norte Grande asentamientos agrícolas similares al de Guatin y, aunque en algunos casos se han detectado elementos arquitectónicos parecidos, el contexto cultural en que se encuentran insertos es diferente.

\section{Discusión y conclusiones}

Se ha elegido el criterio topográfico como principal rasgo diferenciador de los conjuntos de estructuras y por ende de las ocupaciones, puesto que en gran medida reflejan los mecanismos de adaptación del hombre a su medio. Esto no significa caer en un determinismo geográfico, pero sí confirma la importancia que adquiere dicho medio en desiertos de altura.

La presencia en Guatin de una superficie plano inclinada en el sentido del escurrimiento, cruzada por dos ríos endorreicos de régimen permanente, la hizo un hábitat ideal. Así, los asentamientos precerámicos ocupan las lomas que rodean Guatin, donde construyen sus talleres y habitaciones. El fondo plano, durante este período, es utilizado como sitio de caza, como lo evidencian las diseminadas puntas de proyectil que en ella se encuentran.

En el Agroalfarero Medio o Tardío el hombre ocupa definitivamente el plano, comenzando a modificar el paisaje. Este hombre es principalmente agricultor y por ende aprovecha al máximo el suelo apto para el cultivo.

Probablemente los primeros en introducir prácticas agrícolas en Guatin son los portadores de la cerámica negra pulida, pero por desgracia sus restos se encuentran muy derruidos. Por la presencia de algunos fragmentos cerámicos negro engobado en campos construidos en lechos secos pensamos que este patrón es introducido en este período, aunque no alcanza gran desarrollo.

Los denominados lechos secos, cuyo origen se debería al paso de un aluvión, poseen en Guatin aproximadamente 4 a $5 \mathrm{~m}$ de ancho y $2 \mathrm{~m}$ de profundidad y en su interior el contenido de humedad es alto, lo que motivó a dichos habitantes a construir sus campos dentro de ellos. En un comienzo los campos sólo tenían subdivisiones interiores de unimuro y probablemente carecían de canal de regadío (caso del E4.13 ext.). Sus habitaciones eran construidas en un costado del lecho y constaban de dos recintos, uno circular y otro semirrectangular, apoyados en un bloque de piedra natural.

Durante este período, comienzan a ser utilizados, además de los lechos, las superficies planas. Es así como encontramos restos de campos de cultivo de tamaño mediano, planta rectangular.

Es, sin embargo, durante la ocupación tardía del rojo violáceo donde se intensifica la transformación del paisaje por el hombre. La construcción de campos de cultivo en lechos secos alcanza su máximo desarrollo, su tamaño aumenta y se introducen nuevas prácticas de regadío, como ser un canal que fluye por un costado del campo, introduciendo sus aguas a éste, por canales secundarios perpendiculares. Entre uno y otro canal secundario, el campo se ha subdividido en dos, mediante una hilera de cantos rodados que tuvo como función evitar la erosión del suelo.

Las estructuras habitacionales del período anterior son ampliadas y se construyen nuevas, de forma rectangular, siempre a un costado del campo y en una cota mayor, consiguiendo así un mayor control del campo y evitando su humedad.

Las superficies planas también son utilizadas. En algunos casos los campos se extienden hasta el borde mismo de los lechos y se encuentran en asociación a habitaciones y a corrales. El regadío se efectúa por medio de canales o acequias, que se han recubierto de una costra calcárea impermeable, como consecuencia del fluir del agua. Obtienen de esta manera un mayor aprovechamiento del suelo y los campos pueden aumentar su tamaño. La domesticación de animales complementa la dieta, consiguiéndose un incremento en el número de habitantes; sin embargo, nunca llega a formarse una aldea y la ausencia de cementerio en el área, sumada a la escasez de restos arqueológicos producto de excavaciones, nos inclina a pensar que las ocupaciones tuvieron un carácter temporal. 
Los asentamientos coloniales abandonan definitivamente el uso del suelo en lecho seco y construyen sus campos en superficies planas, logrando mayor extensión, pero requiriendo nuevas técnicas hidroagrícolas. Se introducen nuevos sistemas de regadío, así por ejemplo, se construye un dique para almacenar las aguas del río Puripica y llevarlas a los campos, mediante canales que en algunos casos son verdaderas obras de arte.

Por datos históricos y etnográficos, sabemos que en algunos de estos grandes campos se cultivó alfalfa, puesto que con el desarrollo minero y el uso del mular como medio de transporte, ésta alcanzó precios ventajosos. En este período los corrales también aumentan su tamaño, pero estos incrementos en la producción agropecuaria no implicaron un aumento demográfico, ya que el número y tamaño de las estructuras habitacionales no crece, consiguiéndose de esta manera acumular un excedente que debieron haber comercializado, con las urbes cercanas, como en centros mineros.
A partir de 1880, aproximadamente, las habitaciones, campos y corrales se trasladan a los pies de las lomas, de cotas relativas mayores. La explicación de este hecho puede encontrarse en el aluvión de 1884, que destruyó parcialmente el área, a raíz del cual los asentamientos deciden ubicarse en cotas mayores y más seguras, como también en la protección que proporcionan las lomas de inclemencias del tiempo, tales como vientos y oscilaciones térmicas. En este período que hemos denominado reciente, la economía se diversifica y los habitantes desempeñan diferentes actividades, con fines de comercialización (caza y crianza de chinchillas, recolección de llaretas y ganadería), reservándose la actividad agrícola para autoconsumo.

Por último, debemos señalar que este primer informe, de carácter descriptivo y de planteo de hipótesis, deberá ser complementado con estudios del complejo estructural precerámico, dando énfasis, entre otros, a problemas de organización social, demografía y patrones de poblamiento.

\section{REFERENCIAS CITADAS}

LE PAIGE, G., 1957-58. Antiguas culturas atacameñas en la cordillera chilena. Anales de la Universidad Católica de Valparaíso. N Nos 4 y 5. Años 1957-58: 15-148.

-1964. El Precerámico en la cordillera atacameña y los cementerios del período agroalfarero de San Pedro de Atacama. Anales de la Universidad del Norte 3. Antofagasta.

- 1965. San Pedro de Atacama y su zona. Anales de la Universidad del Norte 4. Antofagasta.

1973. El valor arqueológico del Museo San Pedro de Atacama. Estudios Atacameños 1.

LATCHAM, R., 1938. Arqueología de la región atacameña. Prensas de la Universidad de Chile, Santiago.

MOSTNY, G., 1949. Ciudades atacameñas. Boletín del Museo Nacional de Historia Natural, XXIV. Santiago.
1971. La subárea arqueológica de Guatacondo. Boletín del MNHN, tomo XXIX. Santiago.

NIEMEYER, H., A. SCHIAPPACASSE e I. SOLIMANO, 1972-3. Padrones de poblamiento en la Quebrada de Camarones (Provincia de Tarapacá). Actas del VI Congreso de Arqueología Chilena. Oct. 1971. Boletín de Prehistoria. Número especial, 1972-73.

NUÑEZ, L., 1972. Cambios de asentamientos humanos en la Quebrada de Tarapacá. Norte de Chile (esquema interdisciplinario). Serie documentos de trabajo $\mathrm{N}^{\circ} 2$. Programa de Arqueología y Museos. Universidad de Chile. Antofagasta.

RISOPATRON, L., 1924. Diccionario geográfico de Chile. Imprenta Universitaria. Santiago.

SERRACINO, S., R. STEHBERG y G. LIBERMAN, 1973. Informes de trabajo: proyecto Guatin. Estudios Atacameños 1. 


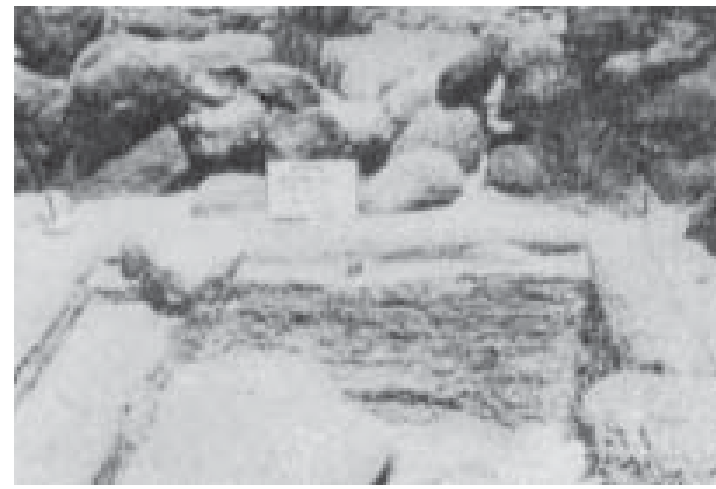

W3.23.1: Vista de excavación en estructura habitacional tardía. Nótese los pisos de la vivienda.

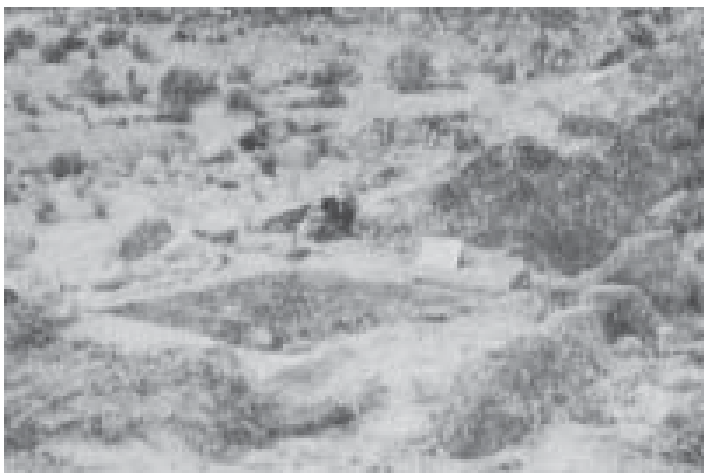

E3.7.1: Vista de excavación dentro de estructura habitacional tardía.

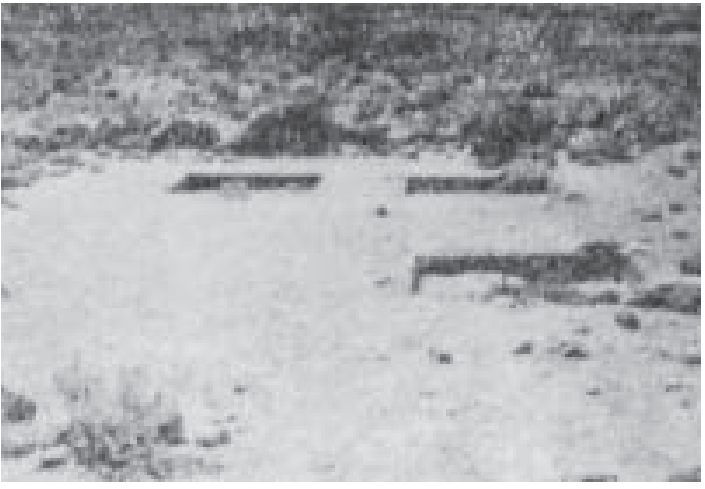

W3.12: Excavaciones dentro de un campo de cultivo.

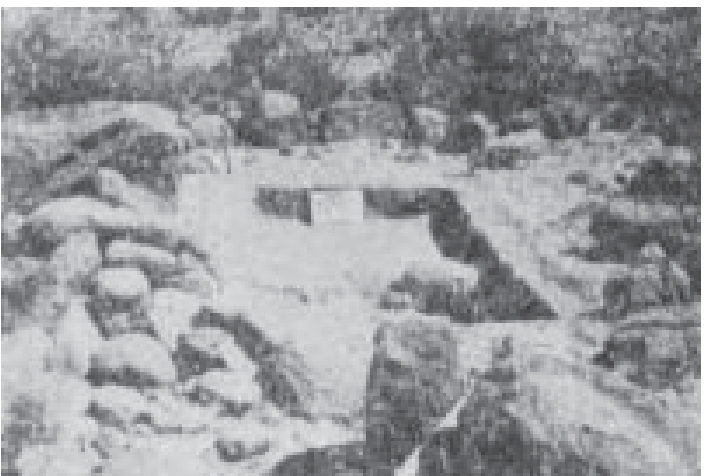

E4.13.2: Vista de excavación en habitación tardía.

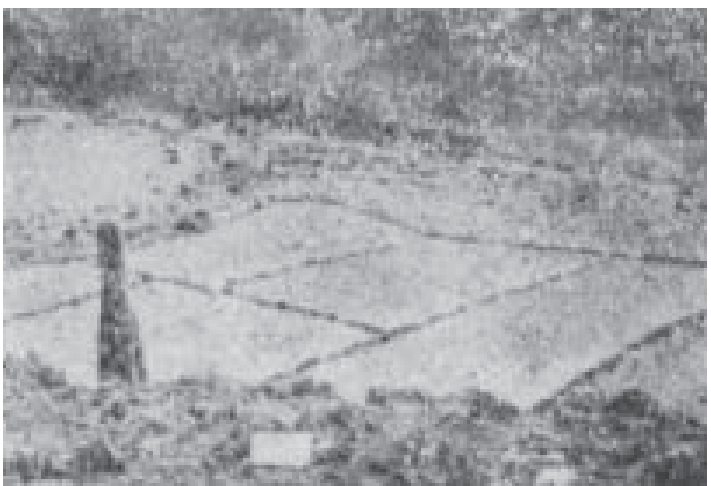

Extremo este: Vista panorámica de campos de cultivo. Tomada desde una loma con taller lítico. 